\title{
CULTURAGALEGA.ORG. ESTRATEXIAS DE DIFUSIÓN CULTURAL EN INTERNET
}

\author{
Manuel Gago Mariño \\ Consello da Cultura Galega
}

\begin{abstract}
A irrupción das novas tecnoloxías denominadas dixitais, a mediados da década dos noventa, tivo un impacto claramente definido na cultura e na sociedade con efectos e modificacións que, en moitos casos, aínda é difícil cuantificar. Sabemos que determinadas características funcionais destas tecnoloxías teñen incidencia directa na práctica cultural: a replicación automática do contido, a distribución deste a un ámbito global con custos mínimos ou reducidos e a democratización das canles de publicación e distribución abriron interrogantes sobre como potenciar, difundir e situar a cultura no novo contorno. Mentres as fronteiras -e as barreiras- físicas se atenúan ou redefinen, a natureza identitaria do ser humano adquire novas dimensións de carácter horizontal: fronte á tradicional identidade étnica, os individuos agrúpanse en comunidades de intereses de carácter transnacional, non territorial, só separadas por fusos horarios e barreiras lingüísticas.
\end{abstract}

\section{A INFORMACIÓN COMO VALOR DE RIQUEZA E DESENVOLVEMENTO}

A literatura sobre a sociedade da información é abundante. Castells indicou no seu momento a clave do novo momento: o principal ben de uso para definir a riqueza das sociedades estriba na cantidade e calidade de información que manexan os seus membros. A información, como valor de cambio, convértese no principal activo de desenvolvemento e a súa produción está vinculada de xeito directo ás industrias culturais. Bastantes datos parecen confirmar este punto: as industrias de información e entretemento medraron de xeito considerable nas últimas décadas, entrando de cheo nos procesos de concentración empresarial e 
diversificando os seus negocios a través da irrupción en diferentes soportes de transmisión. A aplicación de diferentes lóxicas empresariais de racionalización da produción tenderon a diversificar as áreas en que un contido se presenta.

Ao mesmo tempo, os últimos dez anos viviron a eclosión de internet como un gran fenómeno social. A multiplicación dos polos informativos, a aparición de canles de comunicación formadas por grupos, asociacións, entidades e individuos non vinculados ao sector da comunicación está a moldear o carácter da comunicación cibernética. Novas canles descentralizadas, horizontais, sostidas cun baixo custo e formadas por achegas compartidas entre os usuarios agrúpanse esencialmente por comunidades de intereses. A emerxencia do fenómeno blog -especialmente a partir do ano 2002- incrementou a presenza, ao mesmo tempo, de novos actores individuais e colectivos na esfera pública. Este propio concepto, forxado na socioloxía de finais do XIX, atópase nun interesante proceso de redefinición. A participación, a interacción, a publicación sen filtros nin gatekeeping someten a cambios o concepto do que é público e o que non, e a influencia dun contido nos outros advírtese claramente na velocidade de difusión dunha idea a través da rede.

A emerxencia do software libre -sen dereitos industriais nin de autor aos que pagar- parece acompañar o xurdimento dos movementos cidadáns, de creadores culturais de base que se sosteñen na rede para fundamentar a súa actividade cultural. Estas ferramentas, polas que non adoita ser preciso pagar nada, facilitan o intercambio e a distribución de obxectos culturais reducindo ao máximo posible a curva de aprendizaxe e os custos económicos para os emprendedores.

\section{TECNOLOXÍA, INDUSTRIAS CULTURAIS E PERIFERIA}

Estas posibilidades das novas tecnoloxías consideráronse dende un primeiro momento como un desafío estrutural para as culturas periféricas, é dicir, aqueles territorios cun sistema de produción de contidos non inserido nos grandes circuítos de distribución cultural polo seu carácter excéntrico con respecto aos centros 
de decisión e, especialmente, polo emprego dunha lingua cun reducido número de falantes en contextos de convivencia con outras linguas. A mediados da década dos 90 comezou a xurdir a reflexión de que as novas tecnoloxías podían provocar un cambio estrutural en relación á difusión de contidos de culturas minorizadas, salvando obstáculos no mercado interior e proxectando a creación cultural cara ao exterior.

En Galicia, o fenómeno foi advertido dende datas bastante temperás, a nivel teórico. O propio Consello da Cultura Galega formulou en varias ocasións a necesidade de aproveitar a tecnoloxía para a difusión da lingua e da cultura galegas.

A finais da década dos 90, a implantación de internet no país comezaba a introducirse polas áreas urbanas e por un público ben específico: xente nova, de entre 18 e 35 anos, de clase media e estudos universitarios. Esta franxa, dunha considerable actividade e vitalidade, é, ao mesmo tempo, aquela en que o retroceso do galego como primeira lingua falada e escrita é maior, vinculando de xeito especialmente sensible o futuro do idioma coa tecnoloxía e coa interacción dixital.

Nestes eixes, o Consello da Cultura Galega (CCG) comezou a súa actividade na rede. Os servizos na web por parte do Consello iniciáronse no ano 1998, coa creación do web corporativo (www.consellodacultura.org). A partir desta primeira experiencia, o Consello comezou a experimentar con tecnoloxías e servizos. O establecemento de canles estables de información ou a transmisión dos eventos públicos en directo a través de audio foron algunhas das primeiras experiencias. En novembro do ano 2000, o CCG puxo en marcha culturagalega.org, o portal de divulgación cultural en internet.

\section{A FILOSOFÍA EDITORIAL DE CULTURAGALEGA.ORG}

Culturagalega.org naceu co obxectivo de dirixirse a unha franxa de poboación situada na mocidade. O produto, con vocación de aproximarse a públicos de sensibilidades moi diferentes, 
baséase dende entón nunha combinación de tres elementos: información, servizos e entretemento, que o achegan a unha experiencia máis próxima, nos soportes convencionais, a unha cadea de televisión, na que as franxas horarias se especializan para diferentes públicos. En culturagalega.org, a enorme amplitude de contidos permite esta certa segmentación do público en función dos seus intereses particulares nunha industria cultural en concreto.

Culturagalega.org naceu dende unha perspectiva multimedia e destinado a operar na franxa de público antes mencionada. $\mathrm{Na}$ concepción do produto, isto foi decisivo. A clave era tentar aproximarse ás prácticas de consumo cultural empregadas polos usuarios e relacionalos coa cultura galega. Deste xeito, a información cultural foi concibida dende o primeiro momento como un produto multimedia, distribuído en imaxe, texto, audio, vídeo e libro dixital; na presentación de cada un destes produtos, o coidado, o acento, está na concepción, na forma de presentar, na preocupación por establecer límites de comprensión a contidos que, debido á natureza de internet, poderían durar ata o infinito. Ao mesmo tempo, concibíase como un medio que non entraba en competencia con outros, senón que baseaba parte da súa filosofía editorial precisamente en favorecer a navegación interna entre sitios.

\section{A CONVERXENCIA ENTRE INSTITUCIÓN E MEDIO}

A creación dun medio de comunicación nunha institución cunha forte dinámica investigadora e científica supuxo a incardinación do portal como unha estrutura transversal á propia organización do Consello da Cultura Galega. Culturagalega.org foi concibido como unha factoría que conectaba a produción cultural interna, do CCG, nun produto unificado coa produción externa da cultura galega. Deste xeito, en culturagalega.org edítase moito contido xerado a partir de proxectos do CCG de xeito «reciclado» e adaptado para un público xeral, en traballo estreito cos coordinadores de proxecto. 
A información aparece combinada con material extra que engade novas perspectivas sobre o contido central. Culturagalega.org produce noticias e reportaxes durante cinco días á semana que van creando un arquivo diario da cultura. Este arquivo permite comprender cada noticia no seu contexto anterior e engade profundidade sen deter a lectura, pensada en breves cápsulas de decodificación inmediata. Os temas do día, pola contra, son grandes reportaxes que tentan achegarse á cultura galega dende unha perspectiva nova e fresca. Estas reportaxes poden contar con anexos multimedia que permiten ofrecer outra perspectiva e outro xeito de navegación ao usuario.

Os servizos son o contrapunto da narración informativa. Destinados aos creadores culturais, na actualidade están concentrados, especialmente, nos certames e na axenda. Tamén están actualizados diariamente. $\mathrm{O}$ entretemento, pola súa banda, está diseminado por todo o portal. A concepción, dende o punto de vista de culturagalega.org, é de infoentretemento. É dicir, de contido informativo que é consultado en horario de descanso, como alternativa á ficción ou a outros produtos de puro entretemento pero tamén ás cabeceiras xornalísticas de información convencional. As principais áreas de entretemento son os especiais -grandes reportaxes sobre un tema concreto- ou os soportais.

\section{OS SOPORTAIS, UN ESQUEMA DE REPRESENTACIÓN DA PRODUCION CULTURAL}

Os soportais son as áreas máis características do portal. Trátase de subsitios acollidos baixo o dominio culturagalega.org dedicados de xeito monográfico a unha industria cultural concreta. $\mathrm{Na}$ actualidade, culturagalega.org dispón de catro soportais: $\lg 3$ -dedicado á literatura-, rcg -dedicado á música-, bd -dedicado á banda deseñada- e avg -destinado ao sector audiovisual-, nos que figura unha parte moi relevante da produción cultural galega, dos seus creadores e das empresas e entidades que forman parte do sector. A arquitectura de información nos soportais é complexa, pero 
en liñas xerais pódese concibir como un triángulo que define as relacións entre obxectos, entidades e persoas na industria cultural.

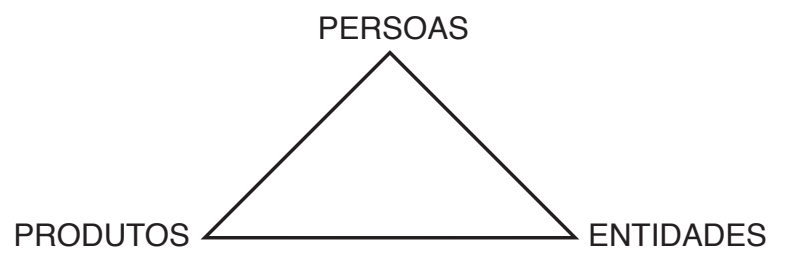

Cada un destes elementos está relacionado, na estrutura lóxica do noso sistema, cos outros, creando unha inmensa marea de relacións entre os diferentes elementos e achegando novos sentidos en cada consulta do usuario.

Por exemplo a AVG (www.culturagalega.org/avg), a zona do audiovisual galego. É posible, a partir dunha ficha técnica de intérpretes dunha película, acceder a todo o currículo artístico dun actor e a outras películas vinculadas. Pero, ao mesmo tempo, saber con que produtoras estivo relacionado ou acceder a un amplo banco de datos multimedia sobre este actor ou actriz. No esquema, o banco de datos increméntase de xeito espectacular con cada nova entrada e permite afondar nos intereses de varios colectivos de usuarios: deste xeito, dende o punto de vista do entretemento, o sistema extrae de xeito independente os bancos de contido multimedia, onde se concentran os tráilers, fotogalerías, bandas sonoras, etc. Dende o punto de vista de información do sector, acontece o mesmo coa información das entidades -produtoras, distribuidoras, etc. - sobre as que interesa localizar información. A relación entre a zona de soportais e a zona de información é automática, ao mesmo tempo. O sistema recupera e relaciona de xeito instantáneo noticias relacionadas coas persoas, entidades ou produtos aos que o usuario está a acceder. Este mesmo esquema funciona para o resto dos soportais, establecendo grandes bancos de datos de escritores ou de autores de banda deseñada. 


\section{UNHA VALORACIÓN EN AUDIENCIA}

$\mathrm{Na}$ actualidade, 5000 persoas acceden diariamente a culturagalega.org co obxectivo de informarse da actualidade da cultura en Galicia. A noción de infoentretemento, que tan relevante é no portal, repercute tamén en parte do tráfico. Culturagalega.org é un medio vespertino, que o público consulta dende as súas casas e, en certa medida, fóra do horario de traballo. Como todos os portais, de todos os xeitos, conviven tamén outros públicos: nos últimos anos, os técnicos e xestores culturais acceden ao portal como ferramenta de traballo fundamental para a toma de decisións. Ao mesmo tempo, moita da audiencia dende o estranxeiro (un 35\%) está formada por profesionais liberais e estudantes que seguen vinculados co seu país de orixe e, en moitos casos, desempeñan algún tipo de actividade vinculada coa creación cultural.

\section{O FUTURO}

Nos últimos anos, a democratización da publicación do contido, antes referida, fíxose máis intensa. A propia noción de cabeceira, no sentido periodístico da palabra, está a reducirse. Culturagalega.org deu pasos, nos últimos anos, destinados a converterse nun servizo que os propios usuarios poden empregar nas súas páxinas. Empregando licenzas de libre publicación de contido, fluxos RSS e outras tecnoloxías, culturagalega.org favorece a difusión cultural permitindo a inclusión de material de contido fóra dela mesma. A mestura con outros contidos diferentes, en produtos novos xestionados polos propios creadores culturais, dá lugar a insospeitadas e frescas novas formas de observar a cultura en internet. As vindeiras décadas serán decisivas para saber como a cultura galega afrontará a chegada, definitiva, da sociedade da información. 